Bangladesh J. Bot. 48(1): 163-168, 2019 (March)

\title{
ISOLATION OF ZIZYBERENALIC ACID AND BIOLOGICAL STUDIES OF ZIZIPHUS MAURITIANA LAM. GROWING IN BANGLADESH
}

\author{
Mohammad Anwarul Karim, Md Khalid Hossain, Md Abdullah Al-Mansur ${ }^{1}$, \\ Md Shafiullah ShaJib ${ }^{2}$ and Mohammad A Rashid* \\ Phytochemical Research Laboratory, Department of Pharmaceutical Chemistry, \\ Faculty of Pharmacy, University of Dhaka, Dhaka-1000, Bangladesh
}

Keywords: Ziziphus mauritiana, Medicinal plant, Triterpenoid, Antioxidant, Cytotoxic

\begin{abstract}
Ziziphus mauritiana Lam. was assessed for phytochemical constituent, antioxidant and cytotoxic activities. Powder prepared from the air-dried leaf was extracted with methanol. The concentrated extract was partitioned with petroleum ether, carbon-tetrachloride, and chloroform. A triterpenoid acid was isolated from the petroleum ether soluble fraction of the plant extract by gel permeation chromatography using Sephadex LH-20 followed by preparative thin layer chromatography over silica gel. The structure of the isolated compound was elucidated as zizyberenalic acid (1) by extensive analysis of its NMR spectral data and confirmed by comparison with published value. The methanol extract $\left(\mathrm{IC}_{50}=7.37 \pm 0.38 \mu \mathrm{g} / \mathrm{ml}\right)$ and its chloroform soluble materials $\left(\mathrm{IC}_{50}=24.14 \pm 0.53 \mu \mathrm{g} / \mathrm{ml}\right.$ ) produced strong antioxidant effect where it was comparable to standard agent tert-butyl-1-hydroxy toluene $\left(\mathrm{IC}_{50}=32.47 \pm 0.72 \mu \mathrm{g} / \mathrm{ml}\right)$ in DPPH free radical assay. The petroleum ether soluble fraction also showed strong cytotoxicity $\left(\mathrm{LC}_{50}=1.31 \pm 0.01 \mu \mathrm{g} / \mathrm{ml}\right)$ in brine shrimp lethality assay which was comparable to the standard drug, vincristine sulfate $\left(\mathrm{LC}_{50}=0.31 \pm\right.$ $0.01 \mu \mathrm{g} / \mathrm{ml}$ ). The results of the present study suggest that the plant leaf could be considered as a significant natural source for the development of antioxidant as well as cytotoxic compounds.
\end{abstract}

\section{Introduction}

Plant-derived natural products have significantly contributed for thousand years to treat and/or prevent human diseases. The analysis of drugs developed from natural origin showed that $28 \%$ of drugs are derived from natural product- or directly used as natural product (Newman et al. 2000) and $25 \%$ are plant-derived drugs. It has been also found that, among the 252 essential and basic drugs approved by WHO, 11\%, have been originated from flowering plants (Rates 2001). The indigenous knowledge regarding the medicinal uses of plants from local flora provides an inventory for an accurate source of traditional system of medicines. A recent report published that the ethnopharmacological uses of plant have contributed $80 \%$ to the drugs discovery from 122 plant-derived drugs (Fabricant and Farnsworth 2001). Thus, plant could be a better source to keep pace in the search of new drugs for human ailments.

Ziziphus mauritiana Lam. (Synonym: Z. jujuba, Family: Rhamnaceae) is a flowering tree which is widely grown for its edible fruit and also found in wild, road-side and bushes throughout Bangladesh (Ghani 2003). Leaves of the plant have been found to be useful for the treatment of diarrhea, typhoid, wounds, liver troubles, fever, asthma and as astringent in ethnomedicine (Goyal et al. 2012). Preliminary phytochemical studies reported that the plant leaves contain steroids, reducing sugar, tannins, alkaloids and glycosides (Karon et al. 2011, Parmar et al. 2012). Chromatographic separation of the plant extract led to the isolation of $\alpha$-amyrin, $\beta$-sitosterol,

*Author for correspondence: <r.pchem@yahoo.com>. ${ }^{1}$ Bangladesh Council of Scientific and Industrial Research (BCSIR), Dr. Qudrat-I-Khuda Road, Dhanmondi, Dhaka-1205, Bangladesh. ${ }^{2}$ Department of Pharmacy, Stamford University Bangladesh, 51 Siddeswari Road, Dhaka-1217, Bangladesh. 
$\beta$-amyrin, $\gamma$-fagarine, stigmasterol and lupeol (Hossain et al. 2015). GC-MS analysis of hexane, chloroform and methanol soluble extracts of the plant identified $\alpha$-linolenic acid (26.45\%), palmitic acid (38.55\%) and methyl stearate (15.59\%) as the major constituents (Ashraf et al. 2015). Pharmacological studies on crude extractives of the leaves revealed promising antimicrobial, analgesic, sedative (Karon et al. 2011), antidiarrheal (Hossain et al. 2015), antitumor, antidiabetic, cardiovascular, immunostimulant (Sharma and Gaur 2013), hepatoprotective (Dahiru and Obidoa 2007), anti-inflammatory (Kumar et al. 2017) and phagocytic (Wadekar and Patil 2008) activities. Previous studies reported that chloroform soluble extract of the plant leaves possesses strong in vitro thrombolytic and anticancer effects (Hossain et al. 2015, Ashraf et al. 2015).

It has been reported that different parts of the plant including fruits (Vahedi et al. 2008, Esteki and Urooj 2012), seeds (Mishra et al. 2011, San et al. 2012), roots (Afzal et al. 2017) and barks (Rahman 2012) possess promising antioxidant and cytotoxic activities. Based on the findings of these previous reports, the current study was aimed to investigate the cytotoxic and antioxidant activities of crude methanol extract of leaves of $Z$. mauritiana growing in Bangladesh and its organic soluble extractives. Furthermore, the study was also conducted to isolate compound from its organic fraction which provided zizyberenalic acid (1). In the present study the isolation of zizyberenalic acid (1) and the results of the preliminary bioassays of crude methanol extract and its different organic soluble (petroleum ether, carbon-tetrachloride and chloroform) fractions are reported.

\section{Materials and Methods}

Ziziphus mauritiana leaves were collected from Dhaka, Bangladesh in September 2010 and identified by the scientists of Bangladesh National Herbarium, Mirpur, Dhaka. The experimental works were conducted at Phytochemical Research Laboratory, Department of Pharmaceutical Chemistry, Faculty of Pharmacy, University. About $1 \mathrm{~kg}$ coarse powder of the leaves was soaked in 3.0 litre methanol and kept for 7 days. The whole mixture was then filtered through cotton plug followed by Whatman No. 1 filter paper and the filtrate obtained was concentrated at $40^{\circ} \mathrm{C}$ by a rotary evaporator. The concentrated extract was then air dried to provide solid residue. The weight of the crude methanol extract was $25 \mathrm{~g}$. An aliquot $(10 \mathrm{~g})$ of methanol extract was partitioned to obtain petroleum ether $(2 \mathrm{~g})$, chloroform $(3 \mathrm{~g})$ and carbon tetrachloride $(3 \mathrm{~g})$ soluble fraction by the modified Kupchan method (Van Wagenen et al. 1993).

An amount of $500 \mathrm{mg}$ of petroleum ether soluble fraction was subjected to gel permeation chromatography over Sephadex LH-20 using $n$-hexane-dichloromethane-methanol (2:5:1) to afford 31 fractions. The column fractions were combined together to 3 groups (G1-G3) based on their TLC behavior. G1 was further purified over PTLC (silica gel $60 \mathrm{~F}_{254}, 20 \times 20 \mathrm{~cm}$ ) plate, developed in ethyl acetate-toluene ( $2: 8)$ and the plates were examined under UV lamp (254 and $360 \mathrm{~nm}$ ). A purple colored band was visualized after spraying with $1 \%$ vanillin-sulfuric acid reagent followed by heating in $110^{\circ} \mathrm{C}$ for $2 \mathrm{~min}$. The selected band was scrapped off without spraying and eluted with $100 \%$ ethyl acetate to yield a pure compound $(\mathbf{1}, 3 \mathrm{mg})$.

Zizyberenalic acid (1): White gummy mass, ${ }^{1} \mathrm{H}$ NMR $\left(400 \mathrm{MHz}, \mathrm{CDCl}_{3}\right): \delta(\mathrm{ppm}) 9.67(1 \mathrm{H}$, s, H-2), $6.53(1 \mathrm{H}, \mathrm{s}, \mathrm{H}-3), 4.72(1 \mathrm{H}, \mathrm{s}, \mathrm{H}-30), 4.59(1 \mathrm{H}, \mathrm{s}, \mathrm{H}-30), 2.98(1 \mathrm{H}, \mathrm{m}, \mathrm{H}-19), 1.95(1 \mathrm{H}, \mathrm{s}$, H-28), 1.66 (3H, s, H-29), 1.13 (3H, s, H-27), 1.12 (3H, s, H-26), 0.98 (3H, s, H-25), 0.06 (6H, s, $\mathrm{H}-23,24)$.

The antioxidant activity of Z. mauritiana extractives was determined by DPPH free radical assay as previously described by Brand-Williams et al. (1995). The extractives (2 mg) were dissolved in $200 \mu \mathrm{l}$ of methanol. Then $100 \mu \mathrm{l}$ of solution was taken in test tube each containing 
$2 \mathrm{ml}$ of distilled methanol. Thus, the final concentration of the prepared solution in the first test tube was $500 \mu \mathrm{g} / \mathrm{ml}$. A series of solutions of varying concentrations (500 - $0.78125 \mu \mathrm{g} / \mathrm{ml}$ ) were prepared by serial dilution method. A concentration of $20 \mu \mathrm{g} / \mathrm{ml}(\mathrm{w} / \mathrm{v})$ of DPPH solution was prepared in methanol. Then $2 \mathrm{ml}$ of methanolic extract solution was added to $3 \mathrm{ml}$ of DPPH solution and mixed well. The absorbance of the mixture was obtained at $517 \mathrm{~nm}$ followed by 30 min of incubation in a dark place. A similar experiment was carried out with tert-butyl-1-hydroxy toluene (BHT) which was used as a standard agent to compare the antioxidant activity of the plant extractives. A DPPH solution without any sample was taken as control. The DPPH free radical inhibition in per cent $(\%)$ was calculated as follows: $\%$ inhibition $=\left(1-\mathrm{A}_{\text {sample }} / \mathrm{A}_{\text {blank }}\right) \times 100$ where, $\mathrm{A}_{\text {blank }}$ and $\mathrm{A}_{\text {sample }}$ represent the absorbance of the DPPH solution with and without the test material, respectively. The concentration providing $50 \%$ inhibition $\left(\mathrm{IC}_{50}\right)$ was calculated from the graph by plotting percentage of inhibition against concentration of extract.

The plant extractives were also screened for cytotoxic activity following the brine shrimp lethality bioassay as described by Meyer et al. (1982). Each of extractives (4 mg) was dissolved in $200 \mu \mathrm{l}$ of DMSO (dimethyl sulfoxide). Then $100 \mu \mathrm{l}$ of the prepared solution was added in a test tube containing $5 \mathrm{ml}$ of simulated seawater containing 10 shrimp nauplii. Thus, the final concentration of the prepared solution in the first test tube was $400 \mu \mathrm{g} / \mathrm{ml}$. Then a series of solutions of varying concentrations $(400-0.78125 \mu \mathrm{g} / \mathrm{ml})$ were prepared by serial dilution. To serve as positive control, vincristine sulfate was used at the same concentration. A DMSO solution without sample and standard drug was used as negative control. The number of survived nauplii was counted after $24 \mathrm{hrs}$ for each concentration and the $\mathrm{LC}_{50}$ (concentration of $50 \%$ lethality) was calculated from per cent mortality.

The analysis of $\mathrm{IC}_{50}$ and $\mathrm{LC}_{50}$ values for antioxidant and cytotoxic effect was calculated using the program Graph Pad Prism (version 6.01), USA, respectively.

\section{Results and Discussion}

Repeated chromatographic separation and purification of the petroleum ether soluble fraction of the methanol extract of leaves of $Z$. mauritiana yielded a triterpenoid identified as zizyberenalic acid (1). No other compounds could be purified because of the limited amount of sample was available.

Compound 1 was obtained as white gummy mass. The compound provided purple colored spot on TLC plate upon spraying of $1 \%$ vanillin-sulfuric acid reagent followed by heating at 110 ${ }^{\circ} \mathrm{C}$ for 2 min which suggested its terpenoid nature. The ${ }^{1} \mathrm{H}$ NMR $\left(400 \mathrm{MHz}, \mathrm{CDCl}_{3}\right)$ spectral data of the compound demonstrated four sharp singlets at $\delta 0.06(6 \mathrm{H}, \mathrm{s}) 0.98(3 \mathrm{H}, \mathrm{s}), 1.12(3 \mathrm{H}, \mathrm{s}), 1.13$ $(3 \mathrm{H}, \mathrm{s})$ which indicated the presence of five methyl groups in the compound. The singlets at $\delta 4.59$ $(1 \mathrm{H}, \mathrm{br} \mathrm{s}), 4.77(1 \mathrm{H}, \mathrm{s})$ and multiplets from $\delta 2.26$ to $2.99(1 \mathrm{H})$ could be attributed to the exomethylene protons at C-30 and C-19 position, respectively. Therefore, a sharp singlet at $\delta 1.66$ for three protons could be assigned to the methyl group at C-29. The spectrum further demonstrated a signal at $\delta 9.70(1 \mathrm{H}, \mathrm{s})$ which could be attributed to an aldehyde proton at $\mathrm{C}-2$ position of ring A. Thus, the proton signal at $\delta 6.53(1 \mathrm{H})$ could be assigned to the olefinic proton at C-3. Accordingly, the structure of the compound was deduced as zizyberenalic acid (1, Fig. 1). The spectral data of this compound was in agreement with that reported for zizyberanalic acid isolated from Paliurus hemsleyanus (Lee et al. 1997) and Allophylus longipes (Zhang et al. 2012). A very related compound, zizyberanalic acid (2), has previously been reported from Z. jujuba (Kundu et al. 1989). Although zizyberenalic acid (1) has been isolated from the fruits of Z. mauritiana (Lee et al. 2003) this is the first-time report of its isolation from the leaves of this plant. 
The extractives of $Z$. mauritiana leaves demonstrated noticeable DPPH free radical inhibition. The methanol extract and its chloroform soluble material displayed strong inhibition of DPPH radicals with the $\mathrm{IC}_{50}$ value of $7.37 \pm 0.38 \mu \mathrm{g} / \mathrm{ml}$ and $24.14 \pm 0.53 \mu \mathrm{g} / \mathrm{ml}$, respectively as compared to the standard agent, tert-butyl-1-hydroxy toluene (BHT) $(32.47 \pm 0.72 \mu \mathrm{g} / \mathrm{ml})$ as shown in Table 1.
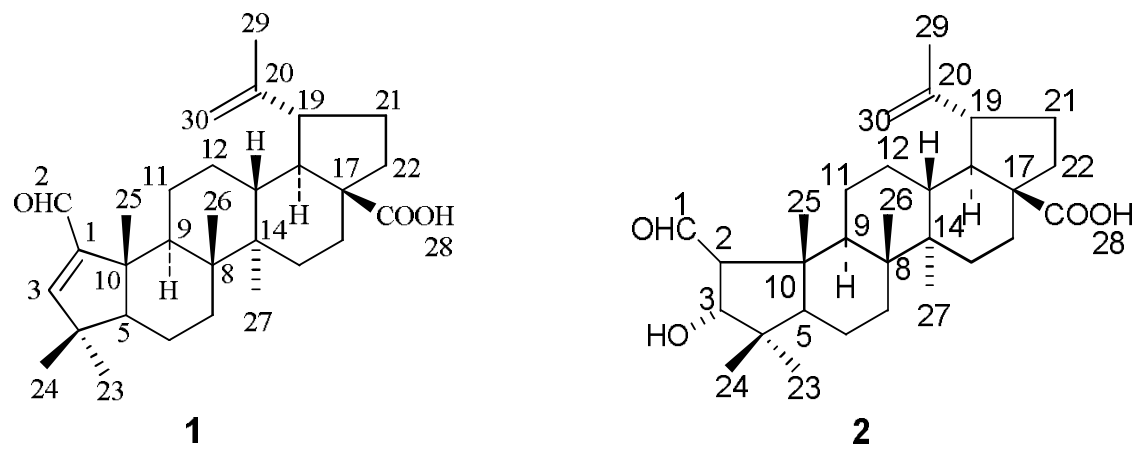

Fig. 1. Chemical structure of zizyberenalic acid (1) and zizyberanalic acid (2).

Table 1. Effect of Z. mauritiana extractives in DPPH free radical inhibition and brine shrimp lethality assay.

\begin{tabular}{llll}
\hline Sl. no. & Treatment & $\mathrm{IC}_{50}(\mu \mathrm{g} / \mathrm{ml})$ & $\mathrm{LC}_{50}(\mu \mathrm{g} / \mathrm{ml})$ \\
\hline 1 & Standard & $32.47 \pm 0.72$ & $0.31 \pm 0.01$ \\
2 & ME & $7.37 \pm 0.38$ & $6.17 \pm 0.12$ \\
3 & PEF & $225.80 \pm 0.84$ & $1.31 \pm 0.01$ \\
4 & CF & $24.14 \pm 0.53$ & $1.38 \pm 0.01$ \\
5 & CTF & $57.24 \pm 0.69$ & $9.43 \pm 0.35$ \\
\hline
\end{tabular}

Data are presented as mean \pm SEM $(\mathrm{n}=3)$. BHT $=$ tert-butyl-1-hydroxy toluene, $\mathrm{ME}=$ methanol extract, $\mathrm{PEF}=$ petroleum soluble fraction, $\mathrm{CF}=$ chloroform soluble fraction, $\mathrm{CTF}=$ carbon tetrachloride soluble fraction of $Z$. mauritiana leaves. Standard for DPPH free radical and brine shrimp lethality assay was tert-butyl-1-hydroxy toluene (BHT) and vincristine sulfate, respectively. $\mathrm{IC}_{50}=$ concentration of $50 \% \mathrm{DPPH}$ free radical inhibition, $\mathrm{LC}_{50}=$ concentration of $50 \%$ lethality.

The organic extractives of $Z$. mauritiana leaves also demonstrated remarkable cytotoxicity in brine shrimp lethality assay which is mentioned in Table 1 . The petroleum ether soluble fraction (PEF) produced strong cytotoxic effect $\left(\mathrm{LC}_{50}=1.31 \pm 0.01 \mu \mathrm{g} / \mathrm{ml}\right)$ which was comparable to standard drug, vincristine sulfate $\left(\mathrm{LC}_{50}=0.31 \pm 0.01 \mu \mathrm{g} / \mathrm{ml}\right)$.

The present study reveals that the leaves of $\mathrm{Z}$. mauritiana possess noticeable antioxidant and cytotoxic activities. Although the cytotoxic (Iqbal et al. 2016) and antioxidant (Al Ghasham et al. 2017) effects of the crude methanol extract of the leaves of Z. mauritiana have been previously reported, the present investigation reports the activities of methanol extract and its different organic fractions of the plant leaves collected in Bangladeshi sample. Further investigation is warranted with the isolated compounds for validation of the pharmacological effect of the plant. Consideration of the bioactive fractions revealed by the present investigations could be useful for 
the isolation of lead compound(s) from the plant. The results of this study suggest that $Z$. mauritiana leaves could be a potential material for the screening of anticancer agents.

\section{References}

Afzal S, Batool M, Ch BA, Ahmad A, Uzair M and Afzal K 2017. Immunomodulatory, cytotoxicity, and antioxidant activities of roots of Ziziphus mauritiana. Pharmacogn. Mag. 13: 262-265.

Al Ghasham A, Al Muzaini M, Qureshi KA, Elhassan GO, Khan RA, Farhana SA, Hashmi S, El-Agamy E and Abdallah WE 2017. Phytochemical screening, antioxidant and antimicrobial activities of methanolic extract of Ziziphus mauritiana Lam. leaves collected from Unaizah, Saudi Arabia. Int. J. Pharm. Res. 6: 33-46.

Ashraf A, Sarfraz RA, Anwar F, Shahid SA and Alkharfy KM 2015. Chemical composition and biological activities of leaves of Ziziphus mauritiana L. native to Pakistan. Pak. J. Bot. 47: 367-376.

Brand-Williams W, Cuvelier ME and Berset CLWT 1995. Use of a free radical method to evaluate antioxidant activity. LWT-Food Sci. Technol. 28: 25-30.

Dahiru D and Obidoa O 2007. Pretreatment of albino rats with aqueous leaf extract of Ziziphus mauritiana protects against alcohol-induced liver damage. Trop. J. Pharm. Res. 6: 705-710.

Esteki T and Urooj A 2012. Antioxidant components and activity in the peel of Ziziphus jujuba Mill. J. Pharm. Res. 5: 2705-2709.

Fabricant DS and Farnsworth NR 2001. The value of plants used in traditional medicine for drug discovery. Environ. Health. Perspect. 109: 69 -75.

Ghani, A 2003. Medicinal plants of Bangladesh: chemical constituents and uses. Asiatic Society of Bangladesh, Dhaka. 434 p.

Goyal M, Sasmal D and Nagori BP 2012. Review on ethnomedicinal uses, pharmacological activity and phytochemical constituents of Ziziphus mauritiana (Z. jujuba Lam., non Mill)-. Spatula DDTamamlayıcı Tıp ve İlaç Geliştirme Alanında Hakemli Dergi. 2: 107-116.

Hossain MJ, Sikder MAA, Kaisar MA, Haque MR, Chowdhury, AA and Rashid MA 2015. Phytochemical and biological investigations of methanol extract of leaves of Ziziphus mauritiana Lam. Boletín Latinoamericano y del Caribe de Plantas Medicinales y Aromáticas, 14: 179-189.

Iqbal K, Iqbal J, Umair M, Farooq U, Iqbal MM, Qamar S and Bashir M 2016. Anti-leishmanial and cytotoxic activities of extracts from three Pakistani plants. Trop. J. Pharm. Res. 15: 2113-2119.

Karon B, Ibrahim M., Mahmood A, Huq AKMM, Chowdhury MMU, Hossain A and Rashid MA 2011. Preliminary antimicrobial, cytotoxic and chemical investigations of Averrhoa bilimbi Linn. and Zizyphus mauritiana Lam. Bangladesh Pharm. J. 14: 127-131.

Kumar RM, Gayatri N, Sivasudha T and Ruckmani K 2017. Profiling of bioactive components present in Ziziphus mauritiana Lam for in-vitro antioxidant and in vivo anti-inflammatory activities. Int. Res. J. Pharm. 8: 19-24.

Kundu AB, Barik BR, Mondol DN, Dey A. and Banerji A 1989. Zizyberanalic acid, A pentacyclic triterpenoid of Zizyphus jujube. Phytocehmnistry. 28: 3155-3158.

Lee SM, Min BS, Lee CG, Kim KS and Kho YH 2003. Cytotoxic triterpenoids from the fruits of Zizyphus jujuba. Planta Med. 69: 1051-1054.

Lee SS, Shy SN and Liu KC 1997. Triterpenes from Paliurus hemsleyanus. Phytochemistry 46: 549-554.

Meyer BN, Ferringni NR, Puam, JE, Lacobsen LB, Nichols DE and McLaughlin JL 1982. Brine shrimp: a convenient general bioassay for active constituents. Planta Med. 45: 31-32.

Mishra T, Khullar M and Bhatia A 2011. Anticancer potential of aqueous ethanol seed extract of Ziziphus mauritiana against cancer cell lines and Ehrlich ascites carcinoma. Evid. Based Complement. Alternat. Med. 2011: 765029.

Newman DJ, Cragg GM and Snader KM 2000. The influence of natural products upon drug discovery. Nat. Prod. Rep. 17: 215-234. 
Parmar P, Bhatt S, Dhyani S and Jain A 2012. Phytochemical studies of the secondary metabolites of Ziziphus mauritiana Lam. Leaves. Int. J. Curr. Pharm. Res. 4: 153-155.

Rahman S 2012. Antioxidant, analgesic, cytotoxic and antidiarrheal activities of ethanolic Zizyphus mauritiana bark extract. Orient. Pharm. Exp. Med. 12: 67-73.

Rates SMK 2001. Plants as source of drugs. Toxicon. 39: 603-613.

San AM, Sithisarn P and Gritsanapan W 2012. Antioxidant activities of Ziziphus mauritiana seed extracts from different extraction methods. Planta Med. 78: 254.

Sharma GN and Gaur A 2013. Ziziphus mauritiana Lam-An overview. Indo. Am. J. Pharm. Res. 3: 45604566.

Vahedi F, Najafi MF and Bozari K. 2008. Evaluation of inhibitory effect and apoptosis induction of Zyzyphus Jujube on tumor cell lines, an in vitro preliminary study. Cytotechnology 56:105-111.

Van Wagenen BC, Larsen R, Cardellina JH, Ran dazzo D, Lidert ZC and Swithenbank C 1993. Ulosantoin, a potent insecticide from the sponge Ulosa ruetzleri. J. Org. Chem. 58: 335 - 337.

Wadekar RR and Patil KS 2008. Effect of Ziziphus mauritiana leaf extracts on phagocytosis by human neutrophils. J. Pharm. Res. 1: 79-83.

Zhang XY, Xiang-Hai C. and Xiao-Dong L 2012. Chemical constituents of Allophylus longipes. Chin. J. Nat. Med. 10: 36-39.

(Manuscript received on 11 July, 2018; revised on 7 September, 2018) 